\title{
SOME NORM INEQUALITIES FOR COMMUTATORS WITH SYMBOL FUNCTION IN MORREY SPACES
}

\author{
Shaoguang Shi And Shanzhen Lu
}

\begin{abstract}
A version of Dini condition is introduced. Some boundedness of commutators with symbol functions belong to Morrey spaces are discussed. The results can be seen as continuity of our recent work [28].
\end{abstract}

Mathematics subject classification (2010): Primary 42B20; Secondary 42B25. Keywords and phrases: Morrey space, commutator, rough kernel.

\section{REFERENCES}

[1] R. Adams And J. XIAO, Regularity of Morrey commutators, Trans. Amer. Math. Soc., 364 (2012), 4801-4818.

[2] A. Calderón, M. Weiss and A. Zygmund, On the existence of singular integrals, Proc. Symposia Pure Math., Amer. Math. Soc., 10 (1967), 56-73.

[3] A. Calderón And A. Zygmund, On existence of certain singular integrals, Acta. Math., 88 (1952), 85-139.

[4] L. Caffarelli and I. Peral, On $W^{1, p}$ estimates for elliptic equations in divergence form, Comm. Pure Appl. Math., 51 (1998), 1-21.

[5] R. Coifman, R. Rochberg And G. Weiss, Factorization theorems for Hardy spaces in several variables, Ann. of Math., 103 (1976), 611-635.

[6] M. Christ, Weak type $(1,1)$ bounds for rough operators, Ann. of Math., 128 (1988), 19-42.

[7] R. Devore And R. Charpley, Maximal functions measuring smoothness, Mem. Amer. Math. Soc., 47, 1984.

[8] Y. Ding, D. FAn AND Y. PAN, Weighted boundedness for a class of rough Marcinkiewicz integrals, Indiana Univ. Math. J., 48 (1999), 1037-1055.

[9] Y. DiNG AND S. LU, Higher order commutators for a class of rough operators, Ark. Mat., 37 (1999), $33-44$.

[10] H. Dong AND D. KIM, Elliptic equations in divergence form with partially BMO coefficients, Arch. Rational Mech. Anal., 196 (2010), 25-70.

[11] J. DuoAndikoetXea And J. Rubio be Francia, Maximal and singular integral operators via Fourier transform estimates, Invent. Math., 84 (1986), 541-561.

[12] X. Duong, J. XIAO And L. Yan, Old and new Morrey spaces with heat kernel bounds, J. Fourier Anal. Appl., 13 (2007), 87-111.

[13] D. FAn, S. LU AND D. YAnG, Regularity in Morrey spaces of strong solutions to nondivergence elliptic equations with VMO coefficients, Georgian Math. J., 5 (5) (1998), 425-440.

[14] D. FAN AND Y. PAN, Singular integral with rough kernels supported by subvarieties, Amer. J. Math., 119 (1997), 799-839.

[15] R. FefFerman, A note on singular integrals, Proc. Amer. Math. Soc., 74 (1979), 266-270.

[16] S. JANSON, Mean oscillation and commutators of singular integral operators, Ark. Mat., 16 (1978), 263-270.

[17] D. KurtZ And R. Wheeden, Results on weighted norm inequalities for multipliers, Trans. Amer. Math. Soc., 255 (1979), 343-362.

[18] P. Lemarié-Rieusset, The Navier-Stokes equations in the critical Morrey-Campanato space, Rev. Math. Iberoamericana, 23 (2007), 897-930. 
[19] G. LU, Embedding theorems on Campanato-Morrey spaces for degrnerate vector fields and applications, C. R. Acad. Sci., Paris, t. 320, Serie I, 1995, 429-434.

[20] S. Lu, Some results and problems on commutators, Front. Math. China, 6 (2011), 821-833.

[21] S. LU AND D. YAN, $L^{p}$-boundedness of multilinear oscillatory singular integrals with CalderonZygmund Kernel, Science in China, 2002, 45A (2), 196-213.

[22] S. LU AND Y. ZHANG, Criterion on Lp-boundedness for a class of Oscillatory singular integrals with rough kernels, Rev. Mat. Iberoamericana, 8 (1992), 201-219.

[23] C. MORRey, On the solutions of quasi-linear elliptic partial differential equations, Trans. Amer. Math. Soc., 43 (1938), 126-166.

[24] E. NAKAI, The Cmapanato, Morrey and Hölder spaces on spaces of homogeneous type, Studia Math., 176 (2006), 1-19.

[25] M. PALUSZYNSKI, Characterization of the Besov spaces via the commutator operator of Coifman, Rochberg and Weiss, Indiana Univ. Math. J., 44 (1995), 1-17.

[26] C. PerEZ, Endpoint estimates for commutators of singular integral operators, J. Funct. Anal., 128 (1995), 163-185.

[27] A. SEeger, Singular integral operators with rough convolution kernels, J. Amer. Math. Soc., 9 (1996), 95-105.

[28] S. SHI AND S. LU, Some characterizations of Campanato spaces via commutators on Morrey spaces, Pacific J. Math., 264 (2013), 221-234.

[29] S. SHI AND Z. FU, Boundedness of sublinear operators with rough kernels on weighted Morrey spaces, J. Funct. Spaces. Appl., 2013, ID: 784983, 9 pages.

[30] Y. Sun, C. WANG AND Z. ZHANG, A Beace-Kato-Majda blow up criterion for the 3-D compressible Navier-Stokes equations, J. Math. Pures Appl., 95 (2011), 36-47.

[31] H. TRIEBEL, Theory of Function spaces II, Birkhäuser Verlag, Basel, 1992.

[32] D. YAN, Some problems on multilinear integral operators and oscillatory singular integral operators, Ph. D. Dissertation, Beijing Normal Univ., 2001.

[33] Da. Yang, Do. YANG And Y. Zhou, Localized Morrey-Campanato spaces on metric measure spaces and applications to Schrödinger operators, Nagoya Math. J., 198 (2010), 77-119. 